\title{
A NEW GENUS OF REDUVIIDE.
}

\author{
By E. Bergroth, \\ Fitchburg, Mass.
}

Among some Hemiptera received some time ago from the desert regions of northwest Argentina, there was a very remarkable Reduviid, by its color, the strueture of the short head and broad, laterally not sinuated but reflexed pronotum and the whole facies closely resembling a Coreid. So strong is the likeness that I had placed it anıng my material of Coreidæ, and it was not until an attempt to determine it that its Reduviid nature revealed itself.

\section{Psammolestes gen. nov.}

Corpus robustum, oblongo-ovatum, opacum. Caput latitudine sua paullulo longius, pronoto paullo brevius, parte postoculari antcoculari triplo breviore et nonnihil latiore, pone oeulos lateribus callosa, basi subito constricta, parte anteoculari aeque lita ac longa, inter oculos et apicem tuberculorum antenniferorum subparallela, tylo apicem truncatum versus dilatato, jugis apicem versus divergentibus, tylo aeque longis, oculis magnis, subglobosis, maximam partem altitudinis capitis occupantibus, ocellis atque oculis aeque late distantilıus, ad hos valde approximatis, tuberculis antenniferi se supero visis libere porrectis et breviter cylindricis, antennis ab oculis quam ab apice capitis paullo longius insertis, brevibus, basin pronoti haud attingentibus, articulo primo brevissimo, incrassato, latitudine sua paullo longiore, apicem capitis haud attingente, articulo secundo latitudini spatii interocularis cum uno oculo subaeque longo, tertio secundo nonnilil breviore, quarto tertio parte tertia breviore, rostro valde depresso, spatio interoculari inferiore latiore, gulam subtangente, marginem anticum prosterni attingente, articulo primo medium partis anteoeularis attingente, secundo primo fere duplo longiore, tertio primo paullo breviore. Pronotum transversum, apice vix sinuatum, marginibus lateralibus rectis, reflexis, antice in tuberculum porrectum breviter conicum productis, angulis humeralibus et basalilus rotundatis, non prominulis, impressione transversa disci ante medium sita sat profunda sed latera non attingente, carinis duabus longitudinalibus parallelis obtusis interrupta, his carinis antice in medium lobi antici continuatis, postice etiam in lobum posticum breviter productis, deinde retrorsum leviter divergentibus et sensim obsolescentibus. Scutellum aequilateraliter triangulare, leniter convexum, apice horizontali, vix producto. Sulcus stridulatorius prosterni latus, leviter impressus. Mesosternum medio gibbum, parte giblsosa longitudinaliter leviter impressa. Hemelytra abdomine angustiora. Abdomen lateribus integrum. Pedes breves, antici leviter, posteriores magis distantes, anteriores suba cgue longi quam postici breviores, femoribus omnibus crassiusculis, inermibus, posticis medium ventris nonnilil superantibus.

Allied to the genus Conorhinus Lap., but at once distinguished 
by the structure of the head and pronotum, the gibbous mesosternum, and a quite different facies.

Psammolestes coreodes sp. nov.

Luride testaceus, ubique plus minusve fusco-conspurcatus, cellulis membranæe maxima parte fuscis, margine abdominis in omnibus segmentis maculis duabus oblongis nigris notato, una ad basin, altera mox pone medium, ventre lineis tribus longitudinalibus fuscis signato, linea media parum distincta, lineis exterioribus irregularibus, hic et illic interruptis. Antennae breviter puberulae, articulis duobus ultimis praeterea setis rigidis semierectis parce restitis, his articulis (basi tertii excepta) et apice articuli secundi infuscatis. Rostrum setulosum. Pronotum longitudine media 2-3 latius, lobo postico antico duplo et dimidio longiore. Hemelytra ( ( ) abdomine paullo breviora. Alae dilute lacteae. Segmentum sextum ventrale ( $q$ ) medio segmentis quinto et quarto dimidioque tertii unitis aeque longum. Pedes densius fusco-rariegati, tibiis apice fuscis. Long. ㅇ $15 \mathrm{~mm}$.

Argentina (Chaco de Santiago del Estero, Rio Salado).

N. B. Attempts have been made of late to use the name Triatoma Lap., instead of Conorhinus. As the name Triatoma was proposed under the misconception that the antennæ are threejointed in this genus, and as it therefore was rejected by Laporte himself as inappropriate and misleading and altered to Conorhinus in the same paper, there is, however, no sufficient reason to discard the name by which the genus has been known nearly eighty years. 

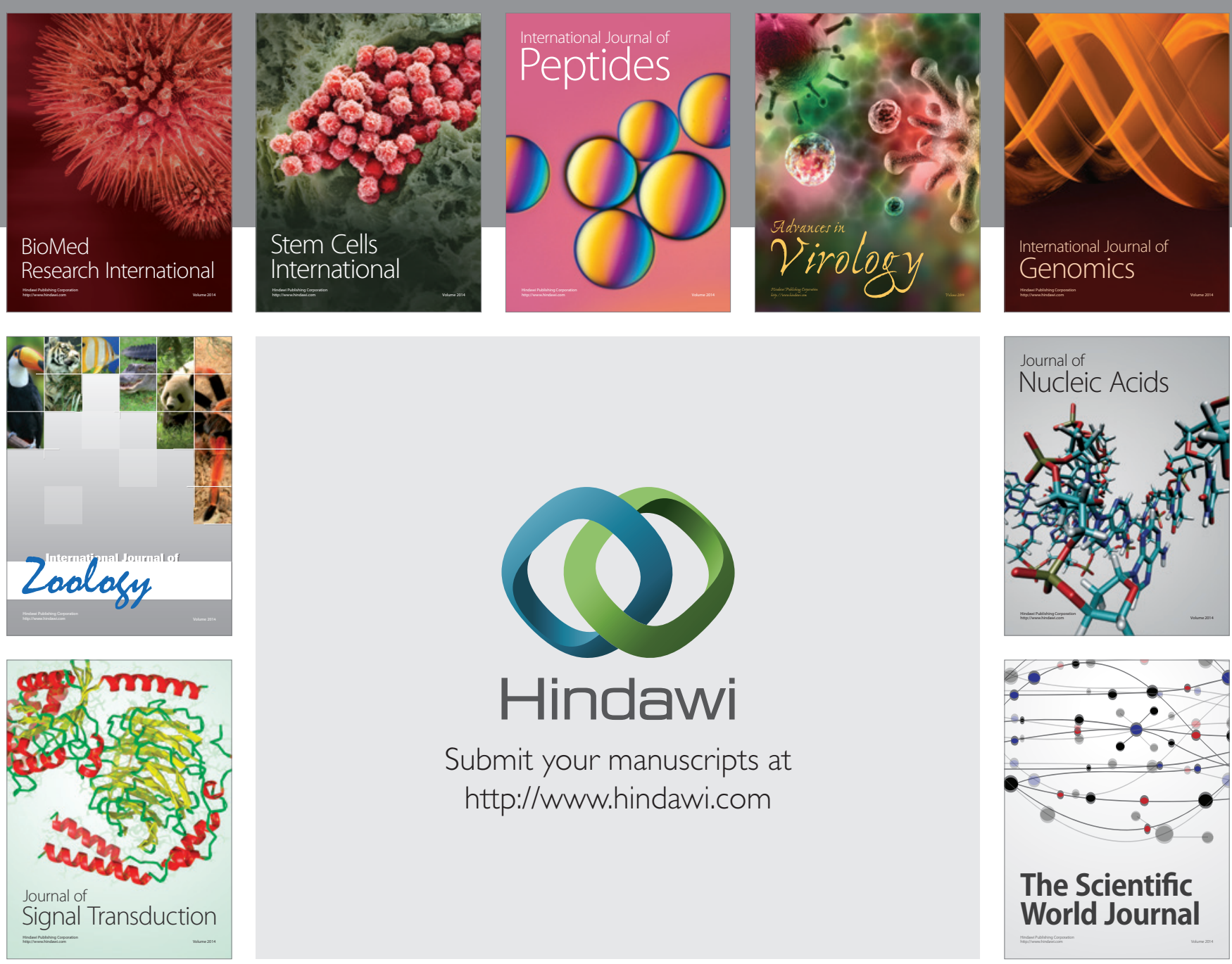

Submit your manuscripts at

http://www.hindawi.com
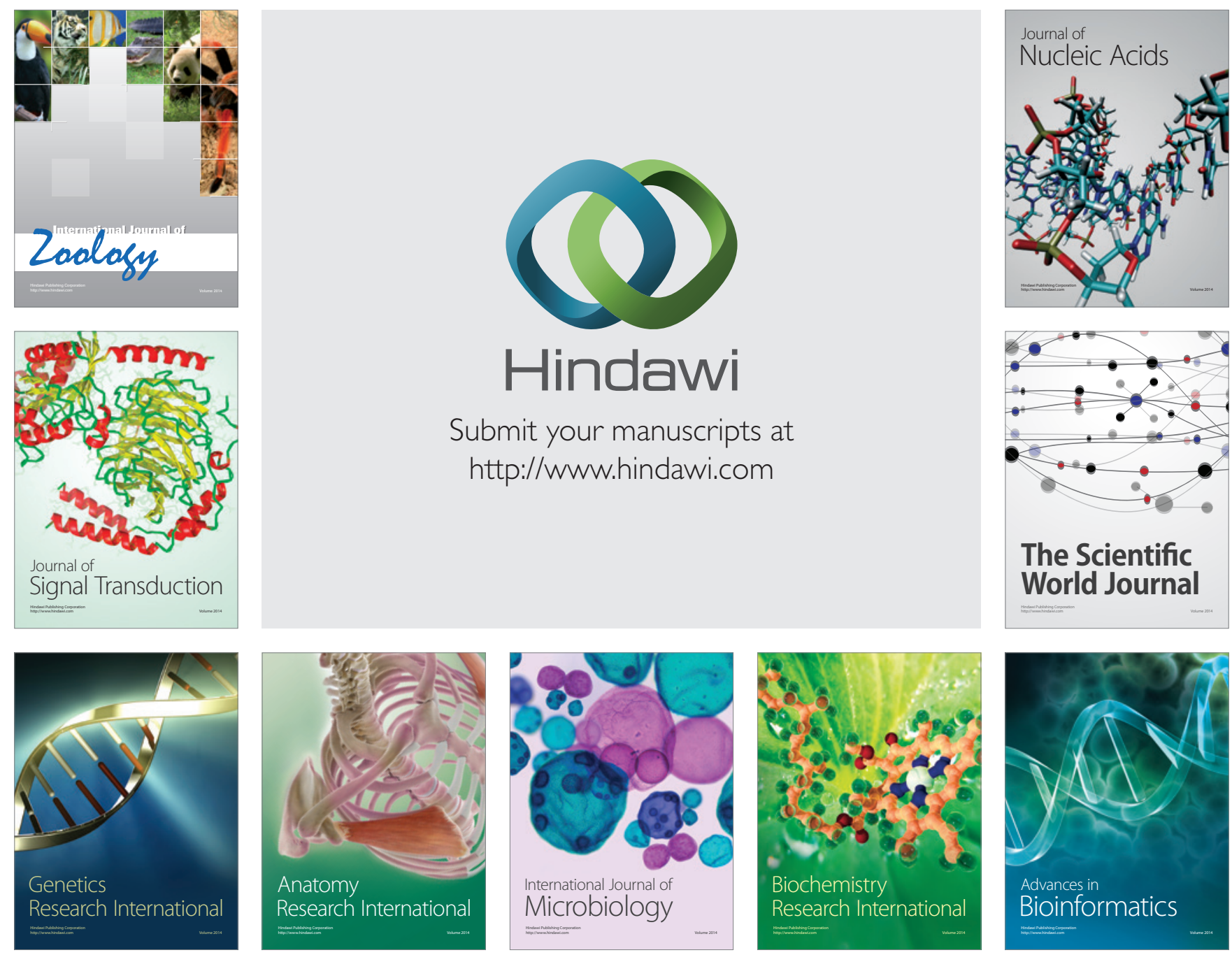

The Scientific World Journal
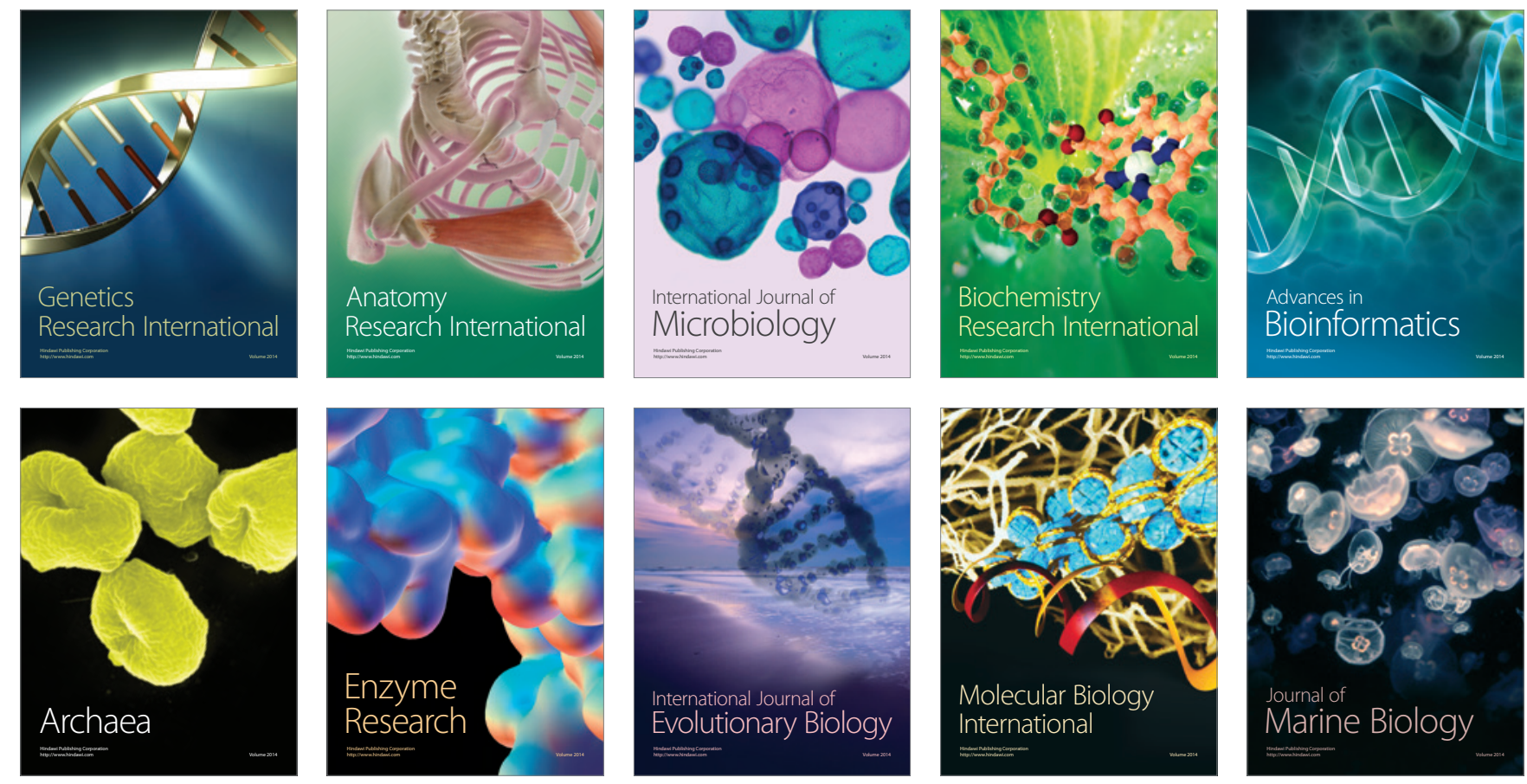